\title{
Dietary macronutrients and glucostatic control of feeding
}

\author{
BY R. JAMES STUBBS \\ The Rowett Research Institute, Greenburn Road, Bucksburn, Aberdeen AB2 9SB
}

Jean Mayer (1955) described in detail the glucostatic theory of energy balance and food intake regulation. At the time this was the most comprehensive attempt to explain theoretically feeding behaviour and energy balance in terms of interactions at the level of intermediary metabolism. Mayer (1955) took the basic energy balance equation (energy balance $=$ energy expenditure \pm stores) and broke it down into its key components which are the intake, oxidation and storage of the macronutrients alcohol, protein, carbohydrate and fat. He suggested that peripheral carbohydrate utilization may produce signals that feed back to influence short-term energy intake. Kennedy's (1953) lipostatic hypothesis provided an explanation of how longer-term energy imbalances can be corrected. Mayer (1955) proposed that any model of short-term energy balance regulation should fulfil the following criteria: (1) it must be integrated with the metabolic processes that mediate between energy input and output; (2) it must be compatible with the known characteristic of the central nervous system (CNS); (3) it must be able to account for the effects of changes in the environment that alter energy expenditure; (4) it must account for the known effects that metabolic hormones exert on food intake and metabolic disorders, e.g. diabetes; (5) it must account for the phenomena of hunger and satiety.

Mayer (1955) also proposed that any model of long-term energy balance regulation should satisfy the following criteria: (1) it must account for the relative constancy of body weight in normal individuals; (2) it must account for the fact that body weight can equilibrate at a new level, if perturbed by sustained environmental influences; (3) it must account for the fact that disorders of metabolism and/or appetite regulation can lead to a change in body weight which subsequently stabilizes at a new level; (4) it must account for the transition from rapid weight gain to a more elevated, stable body weight; (5) it must indicate how long-term regulation of energy balance is articulated with, corrects and operates through the short-term mechanism. Thus, 40 years ago, the key principles underlying research into the metabolic control of body-weight regulation had been outlined, including the rationale for suggesting that the major driving force influencing appetite regulation is glucostatic in nature.

\section{CURRENT UNDERSTANDING OF NUTRIENT BALANCE}

To consider how post-absorptive events could feed back to influence energy intake, it is useful to invoke a basic model of how the system works, and to momentarily ignore the multi-factorial complexity of feeding behaviour. We can consider energy balance simplistically at the level of nutrient balance, as depicted in Fig. 1, to attempt to understand the most likely points at which energy balance regulation can occur.

Energy is taken in the form of the dietary macronutrients alcohol, protein, carbohydrate and fat, and (except for alcohol) deposited in bodily stores. Once ingested, energy and macronutrients are partitioned between oxidation and storage on the basis of 


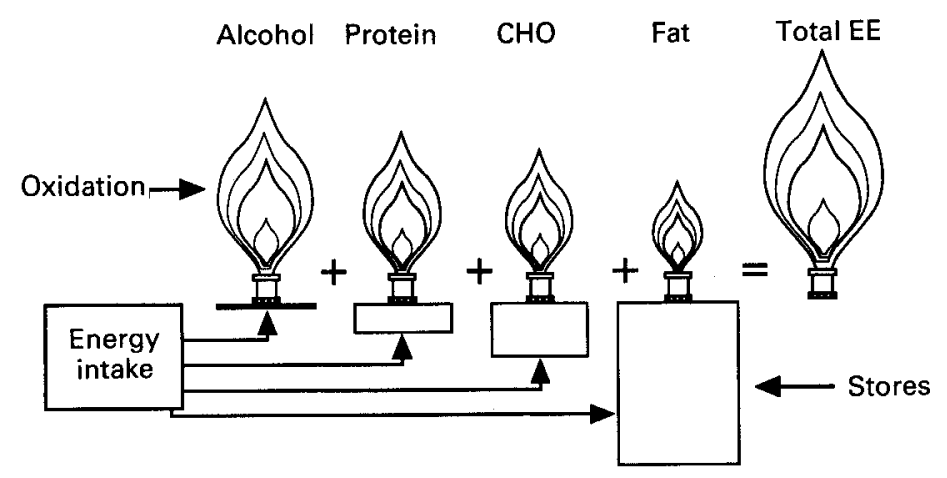

Fig. 1. A schematic representation of energy balance at the level of nutrient balance. The large flame represents total energy expenditure (EE) which is contributed to by the energy expended in the oxidation of the metabolic fuels. The height of the small flames represents the relative (not to scale) tendency to oxidize each nutrient, subsequent to its ingestion. The size of the fuel store underneath each flame represents the relative storage capacity of the body for each macronutrient. $\mathrm{CHO}$, carbohydrate.

the following constraints: (1) when body size, composition and levels of physical activity are taken into account, energy expenditure is remarkably constant (Miller \& Blyth, 1953; Halliday et al. 1979; Cunningham, 1980; Garby et al. 1988). There is little scope to dispose of excess energy intakes by increasing metabolic turnover through mechanisms of adaptive thermogenesis. This in turn suggests that the major factors influencing energy balance are physical activity and feeding behaviour; (2) another key feature of this system is that the storage capacity for the macronutrients varies from virtually zero for alcohol, labile and limited for protein and carbohydrate, to potentially very large indeed for fat (Flatt, 1987). There is a clear trend or hierarchy in the extent to which the dietary macronutrients can be stored; (3) furthermore, under Western diet conditions, the net interconvertibility of the dietary macronutrients is limited (Jéquier, 1992). This of course does not mean that de novo lipogenesis from carbohydrate cannot occur in humans (see Acheson et al. 1988). It does mean, however, that the initial physiological response to large carbohydrate intakes is that carbohydrate oxidation and storage will be greatly elevated. Once these processes are saturated, de novo lipogenesis will occur.

Because of these key features of this system, dietary macronutrients are not metabolically handled as a simple energy currency which is immediately interchangeable. This has led to the suggestion that not all energy is equal with respect to dietary macronutrients. From a purely thermodynamic viewpoint, all energy is approximately equal, but not all energy is handled the same way subsequent to ingestion. At one end of the spectrum is alcohol, which cannot be stored and is immediately oxidized. As a person's energy expenditure is relatively constant at constant activity, the increased obligatory oxidation of alcohol will lead to a suppression of the oxidation of other metabolic fuels - usually fat (Shelmet et al. 1988; Suter et al. 1992). Similarly, the immediate stores of proteins and of carbohydrate are limited and again tend to be modulated by autoregulatory increases in their own oxidation. The ingestion of these macronutrients therefore promotes their own oxidation (Abbot et al. 1988). At the other end of this spectrum is fat, which is very readily stored. The stores of fat are not well regulated by fat oxidation (Flatt et al. 1988). The metabolic fate of fat tends to be a 
secondary response to the balance status of the other macronutrients. Given that there appears to be a hierarchy in the extent to which the stores of the dietary macronutrients are regulated by oxidation, there appears to be considerable scope for the oxidation or stores of one or more macronutrients to exert negative feedback onto subsequent energy intake. This is the logic underlying the nutrient balance hypothesis (Blundell, 1996).

\section{MODELS OF ENERGY BALANCE REGULATION BASED ON MACRONUTRIENT METABOLISM AND STORES}

The simplest possible model of energy intake regulation is that energy flow through the system is somehow monitored, and that increased energy expenditure exerts positive feedback (via depletion of nutrient stores), or that the energy content of nutrient stores is simply monitored by the CNS which adjusts feeding behaviour to maintain energy balance. There is evidence that induced energy deficits produce greater compensation than increments in the energy density of the diet. This is the case when the energy density of some meals is modified by using fat or carbohydrate and subjects respond by feeding ad lib. during the rest of the day (Foltin et al. 1988, 1990, 1992; Mattes et al. 1988; Caputo \& Mattes, 1992) or when nutrient manipulations are induced by offering subjects a fixed intake, and subjects' ad lib. intakes are measured on the subsequent day (Heavey et al. 1995). However, macronutrients exert differential effects on energy intake which cannot be explained by a simple energostatic model of energy intake. Furthermore, this model does not explain the apparently poor regulatory feedback that rodents and human subjects appear to receive from an expanded adipose tissue mass. It may be that the status of one or more macronutrients is being monitored by the CNS rather than overall energy balance per se.

Mayer (1955) suggested that the predominant form of energy balance regulation occurred through short-term 'glucostatic' responses that could be corrected by longerterm 'lipostatic' regulation, should short-term regulation be sufficiently perturbed. Mayer (1955) argued that the 'central role of carbohydrate in the economy of the CNS, the lack of its storage, its preferential utilization, the thoroughness of its regulation, and its role in turn as the central regulator of over-all metabolism' were potent arguments for the role of carbohydrate as the key factor which "can successfully be integrated with energy metabolism and its components'.

The present paper is concerned with reviewing the current status of the glucostatic and related glycogenostatic models (Russek, 1963; Flatt, 1987) of energy balance regulation, in the light of what we know today about the way in which macronutrients influence appetite and energy balance regulation.

The glucostatic and glycogenostatic models of energy balance regulation predict that (1) carbohydrate stores or metabolism exert negative feedback on energy intake, (2) that because of such feedback, high-fat (HF) diets (which are low in carbohydrate) will promote excess energy intakes and (3) that manipulation of carbohydrate status (oxidation or stores) will reciprocally influence energy intake. The key question in relation to these models is: 'how useful are they?' Is there evidence that glucostatic or glycogenostatic mechanisms exert a large enough influence on feeding behaviour to be quantitatively important in the laboratory and in real life? To support these models, studies should demonstrate a high probability that changes in carbohydrate status will exert predictable effects on feeding behaviour that are consistent with the predictions of 
these models. Carbohydrate-based models of energy balance regulation are intuitively attractive because the predictions of these models appear to be consistent with the role of fat as a risk factor for weight gain (Warwick \& Schiffman, 1992; Lissner \& Heitmann, 1995) and other diseases (UK Government, 1991), because these predictions can be tested, and because the predictions of these models offer a potential means of manipulating energy balance. Some appreciation of whether these predictions are correct may come from an examination of the way in which dietary macronutrients influence energy balance, both in free-living people and in the laboratory.

\section{DOES DIETARY MACRONUTRIENT COMPOSITION INFLUENCE APPETITE} AND ENERGY BALANCE?

There are now a large number of dietary survey studies which have examined the relationship between various aspects of diet composition and indices of energy balance. Work by DeCastro \& Orozco (1991) suggests that in moderate drinkers, at least, the energy derived from alcohol is not regulated, but is added to the energy derived from other macronutrients contained in foods. This is not entirely surprising since alcohol has pharmacological (depressant) effects which are not likely to suppress energy intake.

The most consistent finding in relation to dietary macronutrients is that protein appears to be the most satiating macronutrient. Studies by DeCastro (1987) and DeCastro \& Elmore (1988) have shown that in free-living subjects, self-recording their food intakes by using food diaries for $7 \mathrm{~d}$ at a time, protein was the most effective at suppressing energy intake, independent of its contribution to total energy. In a recent study by Bingham et al. (1994) the food and energy intakes of 160 post-menopausal women living at home in the Cambridge area were measured on four consecutive days in each of the four seasons. This approach produced $16 \mathrm{~d}$ of weighed intakes per subject kept over 1 year. The proportion of energy intake from protein correlated negatively with total energy intake $(r-0 \cdot 45)$, carbohydrate did not correlate at all with total energy intake $(r 0 \cdot 0)$ and, fat correlated positively with total energy intake $(r 0 \cdot 18)$. We have recently identified similar patterns in a dataset of $7 \mathrm{~d}$ weighed intakes in ninety-eight men and women from the North East of Scotland (R. J. Stubbs, A. M. Johnstone and C. G. Harbron, unpublished results).

Under free-living conditions, where each $1 \mathrm{~g}$ fat contributes $2 \cdot 2-2 \cdot 3$ times more energy to the diet than either protein or carbohydrate, fat intake appears to correlate with greater energy intakes (DeCastro, 1987; DeCastro \& Elmore, 1988; Bingham et al. 1994) and with indices of body fatness (Tucker \& Kano, 1992; Warwick \& Schiffman, 1992). Lissner \& Heitmann (1995) have recently extensively reviewed the epidemiological literature on dietary fat intake as a risk factor for body fatness. They found that the majority of cross-sectional studies show an association between energy-adjusted fat intake and indices of obesity. Furthermore, a number of prospective observational epidemiological studies show that fat consumption is a risk factor for subsequent weight gain. The data derived from recorded intake and epidemiological studies therefore suggest that, excluding alcohol, there are differences in the extent to which ingestion of the dietary macronutrients predisposes people to excess energy intakes, such that the probability of high levels of energy intake is greatest for fat-rich foods and least for protein-rich foods (as a percentage of energy ingested). It is worth examining whether the same relationships hold in the more-controlled but artificial conditions of the laboratory. 
The data derived from laboratory studies have shown that changes in the macronutrient composition of the diet will differentially influence energy intake. Few studies have examined the satiating effects of alcohol in the laboratory. However, a recent study by Tremblay et al. (1995) has provided data that corroborate the DeCastro (1987) findings in free-living people. Subjects were given ad lib. access over $2 \mathrm{~d}$ to meals that were either low-fat (LF) without alcohol, LF plus alcohol, HF with no alcohol, and HF plus alcohol. As the energy density of the meals was increased by adding alcohol and fat the energy intakes of the subjects increased in an unregulated, additive manner.

Protein again appears to be the most satiating of the macronutrients and most consistently suppresses energy intake during feeding studies in the laboratory. It appears that there may be a critical threshold in the amount of protein required to suppress subsequent energy intake, since studies which have found little effect of protein relative to other macronutrient preloads have only used small amounts of energy as protein in the preload (Geliebter, 1979; de Graaf et al. 1992). Hill \& Blundell (1990) found that a high protein (HP) meal $(31 \%$ of $2.1 \mathrm{MJ})$ produced a greater sensation of fullness and a decreased desire to eat, relative to a high-carbohydrate (HC) meal ( $52 \%$ of $2 \cdot 1 \mathrm{MJ})$ of the same energy content. Hill \& Blundell (1986) also found that both obese and normal-weight subjects reduced their subsequent meal intakes by 19 and $22 \%$ respectively after an HP (54\% of $2 \mathrm{MJ})$ meal compared with an $\mathrm{HC}$ meal $(63 \%$ of $2 \mathrm{MJ})$. Barkeling et al. (1990) gave twenty normal-weight women an HP (43\% of $2.6 \mathrm{MJ})$ or an $\mathrm{HC}(69 \%$ of $2.6 \mathrm{MJ})$ lunch and measured the energy intake at a subsequent evening meal. They found that energy intake was depressed by $12 \%$ after consumption of the HP meal. Booth et al. (1970) also found that an HP meal reduced the intake of a subsequent test meal by $26 \%$ relative to a virtually-protein-free meal in normal-weight individuals. At the Rowett Institute a study has been conducted in which subjects were fed on an HP, $\mathrm{HF}$ or $\mathrm{HC}$ weight-reducing diet of $4.18 \mathrm{MJ} / \mathrm{d}$, for 2 weeks per treatment. In post-study interviews the subjects reported feeling much-less hungry on the HP diet than on the other two diets (Whitehead, 1994). Thus, protein appears to be particularly satiating when given in moderate and large amounts and also when included in a weight-reducing diet.

Numerous laboratory studies have now shown that when human subjects or animals are allowed to feed ad lib. on HF energy-dense diets, the subjects consume similar amounts of food but more energy (which is usually accompanied by weight gain) than when they feed ad lib. on lower-fat less energy-dense diets (e.g. Lissner et al. 1987; Stubbs et al. 1995). The ingestion of HF energy-dense diets does not appear to elicit compensatory feeding responses. Interestingly, if single midday meals are covertly manipulated, by increasing or decreasing their energy density using fat or carbohydrate, under conditions where subjects subsequently feed on a range of familiar food items for the rest of the day, compensation appears to be more precise (Foltin et al. 1990, 1992). In experiments where the diet is systematically manipulated over a whole day and subjects eat ad lib., compensation for the fat content of the diet is again poor (Tremblay, 1989, 1992). These observations suggest that both learning and pre-absorptive factors play a major role in meal-to-meal compensation, since, in the Foltin et al. (1990, 1992) studies, subjects are likely to have responded by using previously-learned knowledge to select foods that will bring about appropriate compensation. In studies such as those by Lawton et al. (1993) the capacity to use previously-learned knowledge of foods is more constrained by the composition of the ad lib. diet. 
Fewer studies have compared isoenergetically-dense loads of fat and carbohydrate. Recent work by Rolls et al. (1994) has suggested, that in the very-short term, preloads of carbohydrate have a greater capacity to suppress energy intake at a test-meal $30 \mathrm{~min}$ after the presentation of a preload than do isoenergetically-dense loads of fat. However, other work (Rolls et al. 1991) has found no difference in the satiating efficiency of graded HF- and HC-rich loads of energy. van Stratum et al. (1978) found that isoenergeticallydense $\mathrm{HF}$ and $\mathrm{HC}$ diets produced similar energy intakes over 2 weeks in twenty-two Trappist nuns. These findings again hint that carbohydrate status per se does not perhaps exert powerful negative feedback onto subsequent intake.

Under both free-living and laboratory conditions, the data available do not suggest that dietary carbohydrates per se exert a powerful leverage effect on feeding behaviour. Rather these data tend to suggest that there is a hierarchy in the extent to which the dietary macronutrients suppress subsequent energy intake such that increasing the concentration of protein (per unit energy ingested) suppresses subsequent energy intake to a greater extent than carbohydrate which has a greater effect than dietary fat. Carbohydrate appears to sit in the middle of this hierarchy. Under more artificial conditions when $\mathrm{HF}$ and $\mathrm{HC}$ foods are made isoenergetically dense (for methods, see Stubbs, 1993), this difference in the satiating efficiencies of carbohydrate and fat appears less clear cut. Alcohol, on the other hand, appears to simply bypass the appetite regulatory system. Given its pharmacological properties, it is not surprising that alcohol is not regulated in a manner similar to other macronutrients. Both appetite and macronutrient metabolism and/or balance appear to be profoundly influenced by the composition of the diet ingested; it is, therefore, reasonable to inquire further as to whether these phenomena are related.

\section{NUTRIENT BALANCE AND APPETITE REGULATION}

In recent years there has been a resurgence of interest in whether changes in nutrient balance feed back to influence subsequent energy intake or nutrient selection. Much more work has been done on energy intake than nutrient selection. Over the last 5 years we have been examining the key predictions of carbohydrate-based models of appetite regulation under controlled laboratory conditions. To do this required the use of indirect calorimeters so that measured changes in nutrient balance could be related to subsequent ad lib. energy intakes. In one study, six normal men were each studied three times using a factorial design (Stubbs et al. 1995). They were given ad lib. covertly manipulated LF, medium-fat (MF) and HF (20, 40 and $60 \%$ of energy as fat) diets (in which the energy density of each diet was increased, mainly by increasing the fat content) for $7 \mathrm{~d}$ in a large whole-body calorimeter. Trajectories of macronutrient and energy balance were monitored to assess possible feedback from macronutrient balances on energy intake. As the fat content and energy density of the diet increased, subjects' food intake remained virtually constant and energy intake increased in parallel with the energy density of the diet, leading to a progressively-positive energy balance. This response is typical of feeding studies in which the dietary energy density is increased in the form of fat.

We used a statistical approach to examine how the metabolism of the stores of dietary macronutrients may produce potential feedback signals that can influence the subsequent day's energy intake throughout the $7 \mathrm{~d}$ subjects had continuous ad lib. access to each diet in the calorimeter. Glucostatic and glycogenostatic models of intake regulation predict 
that there will be an inverse relationship between carbohydrate balance and energy intake (Mayer, 1955; Flatt, 1987). In this particular study, and several others (see Warwick \& Schiffmann, 1992), the highest level of energy intake occurred on the diet with the lowest carbohydrate intake. However, in these studies where dietary energy density increases with the dietary fat content, the experimental design tends to favour such a relationship since it would have been difficult for subjects to ingest sufficient food on the LF diet to match the intakes on the HF diet. The key question is whether, under the conditions of the experiment the relationship between previous carbohydrate balance and subsequent energy intake is causative. In order to examine whether this was probable, regressions were conducted using a nodel which used actual (cumulative) nutrient balances and removed the potentially-confounding effects of subject and diet. It was found that the previous day's cumulative balance of carbohydrate and protein was negatively related to the subsequent day's energy intake (and balance), or to a change in energy intake and balance, whereas there was no potentially suppressive effect from the previous day's cumulative fat balance. The effect for protein balance was greater than that for carbohydrate. The same relationship was examined between the metabolism of the macronutrients and the subsequent day's energy intake. The oxidation of each of the macronutrients on $1 \mathrm{~d}$ was negatively related to the subsequent day's energy balance. This effect was again hierarchical, i.e. protein oxidation exerted a stronger potentially suppressive effect on intake than carbohydrate which exerted a marginally stronger effect than fat. Thus, the previous day's cumulative stores and the previous day's absolute $24 \mathrm{~h}$ oxidation of protein and carbohydrate were negatively related to subsequent energy intake. However, while $24 \mathrm{~h}$ fat oxidation was negatively related to the subsequent day's energy intake, alterations in cumulative fat stores were not related to the subsequent day's energy intake. These findings appear to hint at mechanisms which in part underlie the hierarchy in the satiating efficiency of the dietary macronutrients. We interpret these findings as suggesting that it may be the regulation of nutrient balance by obligatory oxidative disposal which underlies the potentially-suppressive effects that a positive protein and carbohydrate, but not fat balance, exert on subsequent energy intake (Fig. 2). In other words, the macronutrients whose balance is most tightly regulated exert suppressive effects on subsequent energy intake, while fat (whose balance is not tightly regulated) does not exert such an effect.

Whilst ostensibly convincing, these findings actually are limited by the fact that they suggest there is a high probability that the regulation of nutrient stores by oxidation exerts potentially-suppressive effects on intake under the conditions of the experiment conducted, which includes the specific dietary manipulation. These statistical relationships are not proof of causation, but evidence in favour of an interpretation. As Mayer himself pointed out, 'When dealing with a problem which can be attacked only behaviouristically and which depends on a multiplicity of variables, the only systematic approach I know is the statistical method of Skinner, who studied the frequency or probability of responses to this or that stimulus' (Mayer, 1955). Bearing these caveats in mind, it may be suggested that there are benefits to be derived from statistical analyses which consider on-going changes in the energy and nutrient balance status of the animal in relation to feeding behaviour.

These interpretations of the relative metabolic contribution of different macronutrients to changes in subsequent intake do not make statements about the importance of nutrient metabolism and post-absorptive events relative to other influences on intake. 


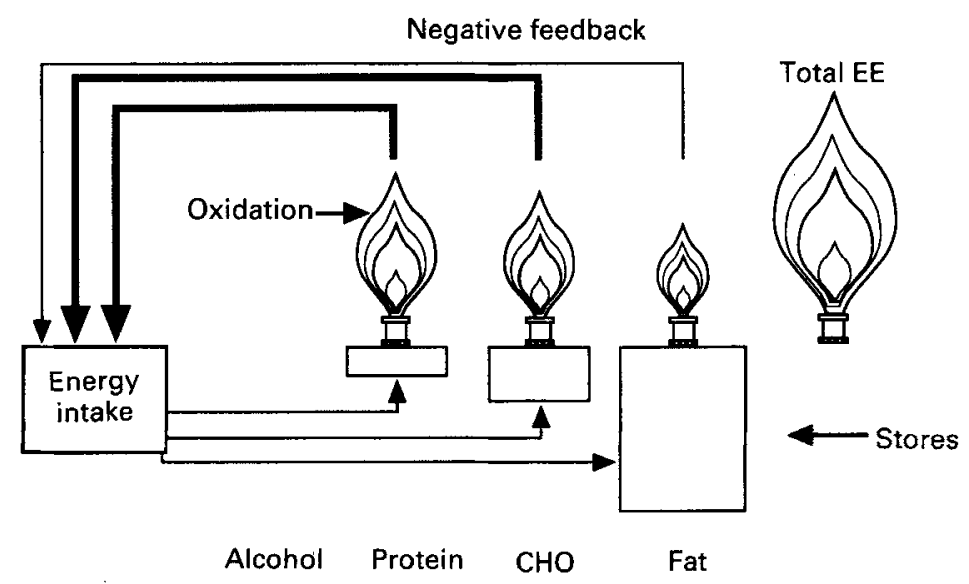

Fig. 2. Interpretation of the possible relationship between nutrient metabolism, storage and appetite. The tendency to autoregulate nutrient stores by oxidation may partially underlie the hierarchy in the extent to which the dietary macronutrients suppress subsequent energy intake. EE, energy expenditure; CHO, carbohydrate.

The quantitative role of metabolic $v$, non-metabolic or nutritional $v$. non-nutritional influences on intake is at present unknown.

\section{WHAT NUTRITIONAL PROPERTIES OF HIGH-FAT DIETS LEAD TO EXCESS ENERGY INTAKE?}

It is pertinent to ask whether excess energy intakes on HF energy-dense diets is underpinned by a drive to maintain carbohydrate status. We therefore conducted a further study to examine whether HF diets still promote higher levels of energy intake when isoenergetically dense relative to LF (HC) diets, as predicted by glucostatic and glycogenostatic models for energy intake regulation (Stubbs, 1993). Six men were each studied three times (factorial design) during $14 \mathrm{~d}$ throughout which they had ad lib. access to one of three covertly-manipulated LF, MF and HF diets, with $2 \mathrm{~d}$ maintenance $(1.4 \times$ BMR; MF) beforehand. These subjects were resident in, but not confined to, a hotel metabolic suite. Energy intakes were $10.69,11.02$, and $10.90 \mathrm{MJ} / \mathrm{d}$ on the LF, MF and $\mathrm{HF}$ diets respectively. The increase in energy intake that occurred in previous studies when the energy density of the diet was increased by addition of fat was not apparent when LF, MF and HF diets were of the same energy density.

Furthermore, it may be that not all fats have the same effect on appetite. It has been suggested that fat produces weak metabolic feedback signals because it is not readily oxidized (Friedman \& Ramirez, 1985). This is consistent with the regression analysis outlined previously. We have recently examined whether covertly substituting a readilyoxidized form of fat, medium-chain triacylglycerol (MCT) for normal long-chain triacylglycerol limits high levels of energy intakes which usually occur on HF energydense diets (Stubbs \& Harbron, 1995). As in all our studies these diets consisted of solid food items. Six men were again each studied three times (factorial design) during $14 \mathrm{~d}$ throughout which they had ad lib. access to one of three covertly-manipulated diets. The 
fat, carbohydrate and protein in each diet (as \% energy) were identical at 62,28 and 10 respectively, with $2 \mathrm{~d}$ maintenance $(1.5 \times \mathrm{BMR}$; MF) beforehand. MCT:LCT was $1: 2$, $1: 1$ and $2: 1$ on the low, (LMCT)-, medium (MMCT)- and high-MCT (HMCT) diets respectively. Energy intakes were significantly lower on the HMCT diet, giving mean values of $13.50,13.67$, and $12.43 \mathrm{MJ} / \mathrm{d}$ on the LMCT, MMCT and HMCT diets respectively. This difference in intakes could not be accounted for by any differences in palatability of the HMCT diet relative to the other two diets. Food intake followed a parallel trend. By day 14 body-weight changes amounted to $+0.45,+0.41$ and $-0.03 \mathrm{~kg}$ respectively. These findings suggested that substitution of a readily-metabolized fat for a less-readily-metabolized fat, can limit excess energy intake and prevent the tendency toward weight gain that is usually produced by HF energy-dense diets. It does not follow from these data that the suppressive effect of MCT was necessarily due to oxidation. This is another piece of corroborative but not conclusive evidence in favour of the idea that increased rates of nutrient oxidation may influence feeding behaviour.

\section{DOES MANIPULATION OF CARBOHYDRATE BALANCE INFLUENCE SUBSEQUENT FOOD OR NUTRIENT INTAKE?}

In two short-term studies we grossly manipulated carbohydrate and fat (but not energy balance) over $1 \mathrm{~d}$ (Stubbs et al. 1993) or $2 \mathrm{~d}$ (Shetty et al. 1994) and found that these manipulations had no effect on the subsequent day's ad lib. energy intakes. This suggests that changes in carbohydrate stores alone may not be the major factor exerting negative feedback on subsequent energy intake and that other aspects of nutrient balance and/or metabolism may be important in exerting a physiological influence on appetite and energy balance in human subjects.

A number of short-term studies have now been conducted where the energy density of breakfasts or lunches has been increased or decreased in the form of fat or carbohydrate and subjects have compensated to a similar extent by altering their energy intakes at subsequent, self-selected meals (Foltin et al. 1990, 1992). In these studies, there was no evidence of macronutrient-specific compensation. Other studies have examined the effects of reducing the energy content of breakfasts by substituting fat-mimetics for real fat (Burley et al. 1991; Rolls et al. 1994). Subjects again compensated for the energy deficit without selectively increasing the intake of any particular macronutrient. In a recent study that examined the relationship between $\mathrm{RQ}$ during exercise and the food quotient $\left(\mathrm{CO}_{2}\right.$ produced: $\mathrm{O}_{2}$ consumed during the biological oxidation of a representative sample of the diet) of the diet selected immediately afterwards, there was no evidence of selection of carbohydrates brought about by previous utilization of carbohydrate stores (N. A. King and J. E. Blundell, unpublished results). This suggests that nutrient imbalances brought about by changes in specific meals or bouts of exercise are not immediately translated into behaviour in terms of altered nutrient selection. However, it may be that there is a period during which subjects learn about the metabolic effects of diets or exercise and subsequently respond in a manner consistent with nutrient specific compensation (for example, see Kyriazakis et al. 1990; Kyriazakis \& Emmans, 1992; Forbes, 1995). If so, this would not have been detected in the studies cited here. On the other hand, metabolic flexibility may simply be sufficient to buffer these short-term nutrient imbalances without recourse to changes in behaviour (Blundell, 1996). 
A number of conclusions can be drawn from the present discussion of the diet-survey and laboratory studies: (1) under 'ecological' conditions there is a hierarchy in the satiating efficiency of the dietary macronutrients (that is the ability for each ingested macronutrient (per MJ) to suppress subsequent energy intake); (2) HF energy-dense diets promote overconsumption of energy relative to LF less-energy-dense diets; (3) in studies where HF and LF (HC) diets are isoenergetically dense the difference in their satiating efficiencies is less pronounced; (4) gross manipulation of nutrient but not energy balance has been found not to influence the subsequent day's energy intake; (5) decrements of nutrient and energy balance are better compensated for than increments, on the same or the following day; (6) there is little evidence that compensation for energy deficits is nutrient-specific, but this conclusion may be limited by experimental design. These findings suggest that, under laboratory conditions at least, energy intake is not directly driven by strong negative feedback from carbohydrate oxidation or stores alone.

\section{NUTRIENT METABOLISM AND 'THE HUNGER STATE'}

Mayer (1955) suggested that any model of energy intake regulation must be able to account for the hunger state. He cited the correlation between arterio-venous differences in blood glucose and hunger as indirect evidence that peripheral carbohydrate utilization influences subjective hunger (Mayer, 1955). Campfield \& Smith $(1986,1990)$ and Campfield et al. (1992) have shown that blood glucose dynamics may be important in meal initiation in both rats and human subjects. More recently, Raben (1995) has shown a high correlation between hunger and indicators of glucose utilization; i.e. area under the curve for plasma glucose, insulin and noradrenaline. We have also examined the relationship between subjective hunger and nutrient oxidation in the study where subjects were given LF, MF and $\mathrm{HF}$ diets in the calorimeter for $7 \mathrm{~d}$ at a time. There was a significant correlation between changes in hunger, and carbohydrate oxidation as time progressed within each inter-meal interval, and between all inter-meal intervals. Since the primary metabolic fuel being oxidized in the inter-meal interval is carbohydrate, this is not surprising. Furthermore, other events also occur at this time (e.g. gastric emptying, absorption of amino acids and lipids), so while such correlations are supportive of metabolic influences on hunger, they are not entirely conclusive. The problem with data such as these is that correlation does not conclusively demonstrate causation. As Blundell (1996) points out 'the key question here is whether or not the different profiles of nutrient oxidation arising from variations in the diet composition can influence behaviour'. Under conditions where the diet is covertly manipulated, it is likely that more extreme changes in nutrient oxidation are required to directly influence behaviour since, under the conditions of the experiment, there is little learning involved in relation to the physiological stimulus. It may be that under normal conditions animals and human subjects learn to anticipate the metabolic consequences of ingesting certain foods, and alter behaviour before such extremes are experienced.

\section{THE INFLUENCE OF DIETARY ENERGY DENSITY $v$. MACRONUTRIENT COMPOSITION ON FEEDING BEHAVIOUR}

In the real world, the energy density of the diet increases as the fat content of the diet increases. Two studies have shown that the passive increase in energy intake that occurs 
when subjects consume HF energy-dense diets was not apparent when the energy density of those diets was $4.18 \mathrm{MJ} / \mathrm{kg}$ (van Stratum et al. 1978) or $4.88 \mathrm{MJ} / \mathrm{kg}$ (Stubbs, 1993). In another study, the effects of varying the energy density of $\mathrm{HC}$ diets was examined (R. J. Stubbs, A. M. Johnstone and C. G. Harbron, unpublished results). The fat, carbohydrate and protein contents in each diet (as \% energy) were identical at 27,60 and 13 respectively, with $2 \mathrm{~d}$ maintenance $(1.5 \times \mathrm{BMR} ; \mathrm{MF})$ beforehand. Subjects ate almost twice as much energy on the diet that contained $6.00 \mathrm{MJ} / \mathrm{kg}$ as the diet that contained $3.00 \mathrm{MJ} / \mathrm{kg}$, with weight gains and losses respectively. This study confirms that with reference to fat and carbohydrate, dietary energy density is a major factor that can override any unlearned metabolic control. However, when the energy density of lunch meals as fat or carbohydrate is increased or decreased and subjects can then select from familiar food items throughout the rest of the day, they compensate for these changes more precisely (Foltin et al. 1990, 1992). It is most likely that under these conditions the subjects are using cues learned before the experiment to select items whose postingestive effects they are familiar with, in order to compensate for changes they had detected in the nutrient density of lunch.

Having demonstrated that the density of fats and carbohydrates in the diet can influence intake it is useful to examine whether macronutrients differentially influence intake when given at isoenergetic levels in the diet. Two recent studies have examined this issue. In the first study six men each spent $24 \mathrm{~h}$ in a whole-body indirect calorimeter on three separate occasions during which they received breakfasts designed to match $75 \%$ of BMR and that contained, on average, $3 \cdot 1 \mathrm{MJ}$ protein $(\mathrm{HP})$, carbohydrate (HC) or fat (HF) respectively, the remainder being split between the other two macronutrients. They were then given an ad lib. diet throughout the rest of the day which comprised (\% energy): 13 protein, 40 fat and 47 carbohydrate, with an energy density of $5.50 \mathrm{MJ} / \mathrm{kg}$. While energy intakes were not influenced when unfamiliar test diets were given, subjective hunger ( $\mathrm{mm}$; distance along a $100 \mathrm{~mm}$ visual analogue scale) was significantly greater during the hours between breakfast and lunch after the HF (26) treatment relative to the $\mathrm{HP}(18)$ or $\mathrm{HC}$ (18) meals, although the HP treatment suppressed hunger to a greater extent than the other two treatments over $24 \mathrm{~h}$ (van Wyk et al. 1995). To test whether overfeeding protein, carbohydrate or fat would differentially influence appetite on the same day and also the subsequent day's food intake, a further study was conducted (Johnstone et al. 1995). Subjects entered the calorimeter at 08.00 hours on day 3 for $48 \mathrm{~h}$. On day 3 (manipulation day), they ate an MF diet at $1.5 \times$ resting metabolic rate (RMR) with an additional $0.6 \times \mathrm{RMR}$ as protein (HP), carbohydrate (HC) or fat (HF). Throughout this day subjects felt significantly more full and less hungry on the HP diet relative to the other two diets. The large suppression of hunger on the HP treatment was immediate but was also related to accelerated protein oxidation, suggesting both pre- and post-absorptive components to this effect. Subjects were in positive balance with respect to each overfed nutrient as compared with the other two diets. However, these effects did not influence the subsequent day's energy intake. The alterations in nutrient balance by the end of day 3 were partially buffered by increases in the oxidative disposal of each overfed macronutrient throughout the subsequent day. It is highly likely that these changes in motivation to eat would have translated into changes in feeding behaviour, if the subjects had been allowed to eat ad lib. on the same day. These studies again suggest that imposing a metabolically 'awkward' load which produces a nutrient-based physiological stress leads to, inter alia, enhanced oxidative disposal of that load and suppressed hunger. 


\section{FURTHER EVIDENCE THAT CHANGES IN NUTRIENT METABOLISM CAN INFLUENCE FEEDING BEHAVIOUR}

The experimental paradigm most often used in human subjects is to alter (usually covertly) the composition of the diet and effectively examine whether the resultant loading of the stores and/or change in the metabolism of certain nutrients produces feedback signals that suppress subsequent food intake. If relatively large changes in the pattern of oxidation of metabolic fuels are important in influencing feeding behaviour then one might expect that the inhibition of nutrient oxidation should stimulate feeding. Friedman \& Tordoff (1986) have shown that glucose and fat oxidation interact to influence food intake. In a remarkable study, rats were given graded doses of 2-deoxyglucose (2DG) which inhibits glucose oxidation by competitive inhibition of phosphohexoisomerase (EC 5.3.8.9) activity. There was a dose-dependent increase in food intake as glucose oxidation was inhibited; a glucoprivic feeding response. Using the inhibitor of long-chain fatty acid oxidation, methyl palmoxirate (MP; which inhibits mitochondrial uptake of long-chain fatty acyl-CoA), they showed a similar dosedependent increase in lipoprivic feeding. However, when both inhibitors were given simultaneously there was a massive synergistic increase in food intake, suggesting that when the metabolism of only one fuel is inhibited the rats may default to another available metabolic fuel. Thus, when no alternative fuels are available endogenously the rat attempts to obtain them exogenously, by feeding. $2 \mathrm{DG}$ has also been found to increase hunger and food intake in human subjects when given at doses of $50 \mathrm{mg} / \mathrm{kg}$ body weight (Thompson \& Campbell, 1977; Welle et al. 1980).

A further study by Friedman et al. (1990) in rats, suggested that it is indeed the oxidation of metabolic fuels that is somehow linked to satiety. MP inhibits the carnitine palmitoyl transferase (EC 2.3.1.21; CPT) transporter that shuttles the long-chain fatty acids across the inner mitochondrial membrane, inside which they are oxidized. Inhibition of this shuttle stimulates food intake. Furthermore, when rats were given MP while consuming a diet rich in MCT, there was no increase in food intake. MCT is not dependent on the CPT transporter to move across the inner mitochondrial membrane to its site of oxidation, suggesting that it really is the inhibition of long-chain fatty acid oxidation by MP that stimulates feeding. Langhans \& Scharrer (1992) have demonstrated that metabolic inhibitors only tend to have potent effects if there is an appreciable amount in the habitual diet of the substrate whose metabolism is being inhibited. On their own, these data do not suggest that inhibition of nutrient metabolism is an important determinant of normal feeding behaviour. However, when combined with the correlations between subjective hunger and indices of glucose utilization (Mayer, 1955; Raben, 1995), or factors related to the oxidative disposal of excess protein (van Wyk et al. 1994; Johnstone et al. 1996) the case becomes stronger. If nutrient metabolism influences feeding behaviour it is appropriate to examine what the linkage might be between peripheral metabolism and feeding behaviour. In Mayer's (1955) terms we must explain the effects of nutrients on feeding behaviour in a manner that is 'compatible with the known characteristic of the CNS'.

\section{NEURAL CONNECTIONS BETWEEN PERIPHERAL METABOLISM AND THE BRAIN THAT MAY BE INVOLVED IN FEEDING BEHAVIOUR}

Recent neuro-anatomical work suggests that both fat and carbohydrate oxidation are separately monitored by the CNS and that these signals are integrated within the brain to 
monitor overall fuel status. Ritter \& Clingasan (1994) have used the anti-metabolic drugs, mercaptoacetate (which causes lipoprivation by blocking mitochondrial acylCoA-dehydrogenases and so reduces $\beta$ oxidation of fatty acids) and 2-DG, as tools to produce lipoprivic and glucoprivic signals. They have then used surgical and chemical lesions, together with neurochemical approaches to examine the neural pathways which sense changes in nutrient metabolism and relay this information to centres of the brain associated with feeding. Using these techniques Ritter \& Clingasan (1994) have provided compelling evidence which suggests that fatty acid oxidation is monitored in the periphery, while glucose oxidation is monitored both in the centre and in the periphery. The authors observe that simultaneous activation of these distinct sensory systems appears to relay information into a central processing area of the brain (the area postrema of the solitary tract) which in turn relays information about fat and carbohydrate oxidation to other areas of the brain associated with feeding. These processes appear to produce an integrated feeding response that takes into account the metabolic availability of both carbohydrates and fatty acids. This is important since the physiological and behavioural responses of the appetite regulatory system need to be able to take account of both changing metabolic requirements and fluctuations in the environmental supply of metabolic fuels. Furthermore, these findings are entirely consistent with the present conclusions about the way in which changes in dietary macronutrient composition influence feeding behaviour. A major challenge for the future is to understand the quantitative importance of dietary macronutrients, the time-course and sites at which they influence feeding, and their relationship with other influences on feeding behaviour. A useful starting point would be to demonstrate that macronutrients do exert differential effects on feeding behaviour which are entirely post-absorptive in nature.

\section{EVIDENCE THAT MACRONUTRIENTS EXERT DIFFERENTIAL, POST-ABSORPTIVE EFFECTS ON FEEDING}

A study by Walls \& Koopmans (1992) has provided strong evidence that the differential effects that macronutrients exert on subsequent food intake can have a strong metabolic component. In their study, amino acids, glucose and lipid were infused intravenously for $30 \mathrm{~min}$ before, and for $17 \mathrm{~h}$ during which rats had ad lib. access to food, over 4-6 d per treatment. The infusions were as follows: amino acids at 42 and $84 \mathrm{~kJ} / \mathrm{d}$, glucose at 142 $\mathrm{kJ} / \mathrm{d}$, lipid at 84 and $168 \mathrm{~kJ} / \mathrm{d}$, and a mixture (\% energy: amino acids, 13; glucose, 50 and lipid, 37) at 84 and $164 \mathrm{~kJ} / \mathrm{d}$. The mean compensation in energy intake (as a percentage of infused energy) was as follows: amino acids 112 (SE 13) and 113 (SE 13), glucose 55 (SE 5), lipid 41 (SE 2) and 42 (SE 4), mixed infusion 74 (SE 10) and 80 (SE 8). The individual macronutrients exhibited a clear hierarchy in the extent to which they suppressed ad lib. intake of a nutritionally-balanced liquid diet, with an energy density of $4.18 \mathrm{~kJ} / \mathrm{g}$ (Isocal; Mead Johnson, Ontario, Canada). Since the infusions completely bypassed the gut, these effects were post-absorptive. A similar, although less-extensive study has been conducted with human subjects (Gil et al. 1991). Healthy men underwent peripheral parenteral administration of nutrient-containing solutions over $3 \mathrm{~d}$, during which time they had access to an oral liquid diet (Ensure, Ross Laboratories, Columbus, $\mathrm{OH}$, USA). These parenteral solutions comprised (as a percentage of RMR): (a) 85, comprising (\%) 40 carbohydrate, 40 fat, 20 amino acids; (b) 68 as carbohydrate; (c) 68 as 
fat. The oral compensation with these solutions was respectively (a) 103, (b) 86 and (c) $43 \%$ of the energy infused. As in the study by Walls \& Koopmans (1992) the mixed infusion was more efficient than glucose at suppressing subsequent intake and carbohydrate was more efficient than the lipid. Thus, the post-absorptive handling of nutrients appears to play a role in the differential effects that macronutrients exert on satiety.

\section{CONCLUSION}

At the present time, these findings and the results of a growing number of studies indicate a redundant system in which changes in nutrient balance do not directly translate into feeding behaviour. Models of energy balance regulation based on feedback from single nutrients appear too simplistic. On the other hand, macronutrients appear to exert potent, quantitatively-important influences on feeding behaviour, which are best explained by considering the combined effects of nutrients in the diet. Some of these influences, such as the hierarchy in the satiating efficiency of the macronutrients, appear consistent across a wide variety of environmental and experimental contexts. The glucostatic and related models of energy balance regulation have established many scientific principles and modes of investigation which are still valid today. These models can be built upon, in the light of our expanding knowledge about macronutrient effects on appetite, to gain a greater understanding of the way in which the diet we eat brings about or disrupts energy balance regulation. We should bear in mind that the study of appetite and energy balance regulation is an evolving multi-disciplinary field of research with numerous experimental approaches and interpretations. It is important both to understand differing research approaches, as well as to view new results critically, as new models evolve (often as refinements of existing ones). Evidence in favour of hypotheses does not prove them and this field is short of conclusive results that are generally applicable. The inconclusive nature of much of the evidence creates an arena for lively debate. It is through such debate across disciplines that considerable progress can be made in understanding the nature and regulation of one of our most fundamental drives, feeding.

\section{REFERENCES}

Abbott, W. G. H., Howard, B. V., Christin, L., Freymond, D., Lillioja, S., Boyce, V. K., Anderson, T. E., Bogardus, C. \& Ravussin, E. (1988). Short-term energy balance: relationship with protein, carbohydrate and fat balances. American Journal of Physiology 255, E332-E337.

Acheson, K. J., Schutz, Y., Bessard, T., Anantharaman, K., Flatt, J. P. \& Jéquier, E. (1988). Glycogen storage capacity and de novo lipogenesis during massive carbohydrate overfeeding in man. American Journal of Clinical Nutrition 48, 240-247.

Barkeling, B., Rossner, S. \& Bjorvell, H. (1990). Efficiency of a high-protein meal (meat) and a HC meal (vegetarian) on satiety measured by automated computerised monitoring of subsequent food intake, motivation to eat and food preferences. International Journal of Obesity 14, 743-751.

Bingham, S. A., Gill, C., Welch, A., Day, K., Cassidy, A., Khaw, K. T., Sneyd, M. J., Key, T. J. A., Roe, L. \& Day, N. E. (1994). Comparison of dietary assessment methods in nutritional epidemiology: weighed records $v .24 \mathrm{~h}$ recalls, food-frequency questionnaires and estimated diet records. British Journal of Nutrition 72, 619-643.

Blundell, J. E. (1996). Food intake and body weight regulation. In Regulation of Body Weight: Biological and Behavioural Mechanisms, Life Sciences Research report 57 [C. Bouchard and G. A. Bray, editors]. Chichester: John Wiley and Sons Ltd.

Booth, D. A., Chase, A. \& Campbell, A. T. (1970). Relative effectiveness of protein in the late stages of appetite suppression in man. Physiology and Behaviour 5, 1299-1302. 
Burley, V. J. \& Blundell, J. E. (1991). Evaluation of the action of non-absorbable fat on appetite and energy intake in lean healthy males. International Journal of Obesity 17, Suppl. 1, 011.

Campfield, L. A. \& Smith, F. J. (1986). Functional coupling between transient declines in blood glucose and feeding behaviour: temporal relationships. Brain Research Bulletin 174, 427-433.

Campfield, L. A. \& Smith, F. J. (1990). Transient declines in blood glucose signal meal initiation. International Journal of Obesity 14, Suppl. 3, 15-33.

Campfield, L. A., Smith, F. J., Rosenbaum, M. \& Geary, N. (1992). Human hunger: is there a role for blood glucose dynamics? Appetite 18, 244 (letter).

Caputo, F. A. \& Mattes, R. D. (1992). Human dietary responses to covert manipulations of energy, fat and carbohydrate in a midday meal. American Journal of Clinical Nutrition 56, 36-43.

Cunningham, J. J. (1980). A re-analysis of the factors influencing basal metabolic rate in normal adults. American Journal of Clinical Nutrition 23, 2372-2374.

DeCastro, J. M. (1987). Macronutrient relationships with meal patterns and mood in the spontaneous feeding behaviour of humans. Physiology and Behaviour 39, 561-569.

DeCastro, J. \& Elmore, D. K. (1988). Subjective hunger relationships with meal patterns in the spontaneous feeding behaviour of humans: evidence for a causal connection. Physiology and Behaviour 43, 159-165.

DeCastro, J. M. \& Orozco, S. (1991). Moderate alcohol intake and spontaneous eating patterns of humans: evidence of unregulated supplementation. American Journal of Clinical Nutrition 52, 246-253.

de Graaf, C., Hulshof, T., Westrate, J. A. \& Jas, P. (1992). Short-term effects of different amounts of protein, fats and carbohydrates on satiety. American Journal of Clinical Nutrition 55, 33-38.

Flatt, J. P. (1987). The difference in storage capacities for carbohydrate and for fat, and its implications for the regulation of body weight. Annals of the New York Academy of Sciences 499, 104-123.

Flatt, J. P., Ravussin, E., Acheson, H. J. \& Jéquier, E. (1988). Effects of dietary fat on postprandial substrate oxidation and on carbohydrate and fat balances. Journal of Clinical Investigation 7, 1019-1024.

Forbes, J. M. (1995). Voluntary Food Intake and Selection in Farm Animals. Wallingford, Oxon: Centre for Agriculture and Biosciences International.

Foltin, R. W., Fischman, M. W., Emurian, C. S. \& Rachlinski, J. J. (1988). Compensation for caloric dilution in humans given unrestricted access to food in a residential laboratory. Appetite 10, 13-24.

Foltin, R. W., Fischman, M. W., Moran, T. H., Rolls, B. J. \& Kelly, T. H. (1990). Caloric compensation for lunches varying in fat and carbohydrate contents by humans in a residential laboratory. American Journal of Clinical Nutrition 52, 969-980.

Foltin, R. W., Rolls, B. J., Moran, T. H., Kelly, T. H., McNelis, A. L. \& Fischman, M. W. (1992). Caloric, but not macronutrient compensation by humans for required eating occasions with meals and snacks varying in fat and carbohydrate. American Journal of Clinical Nutrition 55, 331-342.

Friedman, M. I. \& Ramirez, I. (1985). Relationship of fat metabolism to food intake. American Journal of Clinical Nutrition 42, 1093-1098.

Friedman, M. I., Ramirez, I., Bowden, C. R. \& Tordoff, M. G. (1990). Fuel partitioning and food intake: role for mitochondrial fatty acid transport. American Journal of Physiology 258, R216-R221.

Friedman, M. I. \& Tordoff, M. G. (1986). Fatty acid oxidation and glucose utilisation interact to control food intake in rats. American Journal of Physiology 251, R840-R845.

Garby, L., Garrow, J., Jørgensen, B., Lammert, O., Madsen, K., Sørensen, P. \& Webster, J. (1988). Relation between energy expenditure and body composition in man: specific energy expenditure in vivo of fat and fat free tissue. European Journal of Clinical Nutrition 42, 301-305.

Geliebter, A. A. (1979). Effects of equicaloric loads of protein, fat, and carbohydrate on food intake in the rat and man. Physiology and Behaviour 22, 267-273.

Gil, K., Skeie, B., Kvetan, V., Askanazi, J. \& Friedman, M. I. (1991). Parenteral nutrition and oral intake: Effect of glucose and fat infusion. Journal of Parenteral and Enteral Nutrition 15, 426-432.

Halliday, D., Hesp, R., Stalley, S. F., Warwick, P., Altmann, D. G. \& Garrow, J. S. (1979). Resting metabolic rate, weight, surface area and body composition in obese women. International Journal of Obesity 3, 1-6.

Heavey, P. M., McKenna, A. P. M., Goldberg, G. R., Murgatroyd, P. R. \& Prentice, A. M. (1995). Underfeeding by reduction in fat or carbohydrate intake: effects on energy expenditure, macronutrient oxidation and subsequent food intake in lean men. Proceedings of the Nutrition Society 54, 160A.

Hill, A. J. \& Blundell, J. E. (1986). Macronutrients and satiety: the effects of a high-protein or highcarbohydrate meal on subjective motivation to eat and food preferences. Nutrition and Behaviour 3, $133-144$. 
Hill, A. J. \& Blundell, J. E. (1990). Comparison of the action of macronutrients on the expression of appetite in lean and obese humans. Annals of the New York Academy of Sciences 597, 529-531.

Jéquier, E. (1992). Calorie balance versus nutrient balance. In Energy Metabolism: Tissue Determinants and Cellular Corollaries, pp. 123-128 [J. M. Kinney, editor]. New York: Raven Press.

Johnstone, A. M., Stubbs, R. J. \& Harbron, C. G. (1996). Macronutrients, appetite and day-to-day food intake in man. Proceedings of the Nutrition Society 55, $4 \mathrm{~A}$.

Kennedy, G. C. (1953). The role of depot fat in the hypothalamic control of food intake in the rat. Proceedings of the Royal Society 140B, 578-592.

Kyriazakis, I. \& Emmans, G. C. (1992). Selection of a diet by growing pigs given choices between foods differing in contents of protein and rapeseed meal. Appetite 19, 121-132.

Kyriazakis, I., Emmans, G. C. \& Whittemore, C. T. (1990). Diet selection in pigs: choices made by growing pigs given foods of different protein concentrations. Animal Production 50, 189-199.

Langhans, W. \& Scharrer, E. (1992). The metabolic control of food intake. World Review of Nutrition and Dietetics 70, 1-68.

Lawton, C. L., Burley, V. J., Wales, J. K. \& Blundell, J. E. (1993). Dietary fat and appetite control in obese subjects: weak effects on satiation and satiety. International Journal of Obesity 17, 409-416.

Lissner, L. \& Heitmann, B. L. (1995). Dietary fat and obesity: evidence from epidemiology. European Journal of Clinical Nutrition 49, 79-90.

Lissner, L., Levitsky, D. A., Strupp, B. J., Kalkwarf, H. J. \& Roe, D. A. (1987). Dietary fat and the regulation of energy intake in human subjects. American Journal of Clinical Nutrition 46, 886-892.

Mattes, R. D., Pierce, C. B. \& Friedman, M. I. (1988). Daily caloric intake of normal weight adults: responses to changes in dietary energy density of a luncheon meal. American Journal of Clinical Nutrition 48, $214-219$.

Mayer, J. (1955). Regulation of energy intake and the body weight. Annals of the New York Academy of Sciences 63, 15-43.

Miller, A. T. \& Blyth, C. S. (1953). Lean body mass as a metabolic reference standard. Journal of Applied Physiology 5, 311-316.

Raben, A. (1995). Appetite and carbohydrate metabolism. PhD Thesis, Royal Veterinary and Agricultural University, Copenhagen.

Ritter, S. \& Clingasan, N. Y. (1994). Neural substrates for metabolic controls of feeding. In Appetite and Body Weight Regulation: Sugar, Fat and Macronutrient Substitutes, pp. 77-96 [J. D. Fernstrom and G. D. Miller, editors]. Boca Raton, Fl: CRC Press.

Rolls, B. J., Kim-Harris, S., Fischman, M. W., Foltin, R. W., Moran, T. H. \& Stoner, S. A. (1994). Satiety after preloads with different amounts of fat and carbohydrate: implications for obesity. American Journal of Clinical Nutrition 60, 476-487.

Rolls, B. J., Kim, S., McNelis, A. L., Fischman, M. W., Foltin, R. W. \& Moran, T. H. (1991). Time course of effects of preloads high in fat or carbohydrate on food intake and hunger ratings in humans. American Journal of Physiology 260, R756-R763.

Rolls, B. J., Pirragha, P. A., Jones, M. B. \& Peters, J. C. (1992). Effects of olestra a non caloric fat substitute on daily energy and fat intakes. American Journal of Clinical Nutrition 56, 84-92.

Russek, M. (1963). An hypothesis on the participation of hepatic glucoreceptors in the control of food intake. Nature 197, 79-80.

Shelmet, J. L., Reichard, G. A., Strutches, C. I., Hoeldtke, R. D., Owen, O. E. \& Boden, G. (1988). Ethanol causes acute inhibition of carbohydrate, fat and protein oxidation and insulin resistance. Journal of Clinical Investigation 81, 1137-1145.

Shetty, P. S., Prentice, A. M., Goldberg, G. R., Murgatroyd, P. R., McKenna, A. P. M., Stubbs, R. J. \& Volschenk, P. A. (1994). Alterations in fuel selection and voluntary food intake in response to iso-energetic manipulation of glycogen stores in man. American Journal of Clinical Nutrition 60, 534-543.

Stubbs, R. J. (1993). Macronutrients, appetite and energy balance in humans. PhD Thesis, Cambridge University.

Stubbs, R. J., Goldberg, G. R., Murgatroyd, P. R. \& Prentice, A. M. (1993). Carbohydrate balance and day-to-day food intake in man. American Journal of Clinical Nutrition 57, 897-903.

Stubbs, R. J. \& Harbron, C. G. (1995). Isoenergetic substitution of MCT for LCT: Effect on energy intake in ad libitum feeding men. International Journal of Obesity 19, Suppl. 2, P28 Abstr.

Stubbs, R. J., Harbron, C. G., Murgatroyd, P. R. \& Prentice, A. M. (1995). Covert manipulation of dietary fat and energy density: effect on substrate flux and food intake in men feeding ad libitum. American Journal of Clinical Nutrition 62, 316-330. 
Suter, P. M., Schutz, H. \& Jéquier, E. (1992). The effect of ethanol on fat storage in healthy subjects. New England Journal of Medicine 326, 983-987.

Thompson, D. A. \& Campbell, R. G. (1977). Hunger in humans induced by 2-deoxy-D-glucose: Glucoprivic control of taste preference and food intake. Science 198, 1065-1068.

Tremblay, A., Lavallee, N., Almeras, N., Allard, L., Despres, J. P. \& Bouchard, C. (1991). Nutritional determinants of the increase in energy intake associated with a high-fat diet. American Journal of Clinical Nutrition 53, 1134-1137.

Tremblay, A., Plourde, G., Despres, J. P. \& Bouchard, C. (1989). Impact of dietary fat content and fat oxidation on energy intake in humans. American Journal of Clinical Nutrition 49, 799-805.

Tremblay, A., Wouters, E., Wenker, M., St-Pierre, S., Bouchard, C. \& Depres, J. P. (1995). Alcohol and a high-fat diet: a combination favouring overfeeding. American Journal of Clinical Nutrition 62, 639-644.

Tucker, L. A. \& Kano, M. J. (1992). Dietary fat and body fat: a multivariate study of 205 females. American Journal of Clinical Nutrition 56, 616-612.

UK Government (1991). Health of the Nation. White Paper. London: H.M. Stationery Office.

van Stratum, P., Lussenburg, R. N., van Wezel, L. A., Vergroesen, A. J. \& Cremer, H. D. (1978). The effect of dietary carbohydrate : fat ratio on energy intake by adult women. American Journal of Clinical Nutrition 31, 206-212.

van Wyk, M. C. W., Stubbs, R. J., Johnstone, A. M. \& Harbron, C. G. (1995). Breakfasts high in protein, fat or carbohydrate: effect on within-day appetite and energy balance. International Journal of Obesity 19 , Suppl. 2, P134 Abstr.

Walls, E. K. \& Koopmans, H. S. (1992). Differential effects of intravenous glucose, amino acids and lipid on daily food intake in rats. American Journal of Physiology 262, R225-R234.

Warwick, Z. S. \& Schiffman, S. S. (1992). Role of dietary fat in calorie intake and weight gain. Neuroscience and Biobehavioural Reviews 16, 585-596.

Welle, S. L., Thompson, D. E., Campbell, R. G. \& Lilavivathana, U. (1980). Increased hunger and thirst during glucoprivation in humans. Physiology and Behaviour 25, 397-403.

Whitehead, J. M. (1994). Effects of diet composition on energy expenditure during energy restriction. MSc Thesis, University of Aberdeen. 